




\section{AULA MAGNA ARQUEOLOGIA COMO TRADUÇÃO DO PASSADO NO PRESENTE}

\section{F A B Í O L A A N D RÉ A S I L V A}

UNIVERSIDADE DE SÃO PAULO, BRASIL 
A Arqueologia pode traçar sua trajetória intelectual desde os séculos XV e XVI, no contexto do Antiquarismo e do Classicismo, passando pelo Iluminismo no século XVIII, para então emergir como disciplina científica no século XIX. Para alguns historiadores da ciência, a vocação inicial da Arqueologia, no século XIX, era a construção de uma história da origem e evolução humana no passado ou, em outras palavras, da pré-história da humanidade, tendo como base os vestígios materiais.

No século XX a Arqueologia consolidou-se como campo científico e, especialmente na segunda metade, seu desenvolvimento levou a criação de paradigmas teóricos que expandiram suas abordagem e capacidade explicativa, sempre na direção da multidisciplinaridade. Se, inicialmente, havia uma ênfase na história cultural, a etapa seguinte foi marcada pela diversificação temática e pela compreensão dos processos culturais. Após os anos 1960, a preservação e o gerenciamento do patrimônio arqueológico, ocuparam seu lugar na pauta de discussões de forma mais sistemática, fazendo a Arqueologia sair dos museus e universidades, atingindo o poder legislativo, os órgãos públicos, as organizações não-governamentais, a iniciativa privada e as comunidades locais. Mais recentemente, especialmente a partir dos anos oitenta, a abordagem interpretativa, contextual e simbólica dos vestígios arqueológicos também entrou na agenda de pesquisas. Esse desenvolvimento foi marcado por diferentes escolas teóricas que produziram o que se poderia chamar de uma tensão paradigmática no âmbito da disciplina - que persiste até hoje. A Arqueologia que desde o seu nascimento já dialogava com diferentes disciplinas tornou-se definitivamente pluralista, com muitos pontos de vista, todos igualmente válidos. Ou em outras palavras, diferentes teorias e métodos são usados para responder os problemas de pesquisa.
"A Arqueologia começa a parecer menos como uma disciplina bem definida com claras fronteiras e mais como um tipo fluido de in- terações negociadas. Menos como uma coisa e mais como um pro- cesso" (Hodder 1999:19)

No Brasil, a Arqueologia iniciou no período imperial, sob a influência do pensamento europeu e norte-americano, tanto na prática, quanto na estruturação das instituições (Ferreira 2010). Ao longo desses séculos, passou por diversas etapas de produção científica, na maioria das vezes dentro de instituições (museus e institutos históricos no século $\mathrm{XIX}$, universidades no século $\mathrm{XX}$ e as empresas privadas e ONGs no século XXI). Até a década de 1950 a abordagem arqueológica sempre esteve próxima da Etnologia Indígena, da História, da Geologia e da Bioantropologia, praticada, até aquele momento, por poucos indivíduos com diferentes formações acadêmicas. A ampliação da comunidade dos arqueólogos começa na década de 1950, a partir da consolidação da perspectiva da proteção do patrimônio arqueológico que ganhou espaço a partir da década de 1930 e se consolidou em 1961 com a lei de proteção do patrimônio arqueológico 
(Lei 3294/61) (Rodrigues 2006). Nesta etapa a formação profissional ocorreu dentro de missões científicas (francesas e norte-americanas) patrocinadas por órgãos e universidades públicas, com cursos de extensão e especialização com disciplinas teóricas e práticas, centradas na perspectiva arqueológica, tangenciada por outras disciplinas como a Antropologia, a História, a Geologia, a Biologia, etc. A partir dos anos 1970 começaram a surgir os primeiros pesquisadores com doutorado e o primeiro curso de graduação em Arqueologia. Na década seguinte, consolidou-se a formação em nível de pós-graduação em Arqueologia, primeiramente, vinculada aos Programas de História e Antropologia e, a partir da virada do milênio, com o estabelecimento de programas específicos de Arqueologia - tendência que tem se intensificado nos últimos anos.

Ao longo dessa trajetória intelectual tanto no Brasil como em outros países - a Arqueologia estabeleceu um profícuo diálogo com as diferentes Ciências Naturais, Ciências da Terra e Ciências Humanas. Nos últimos anos, com a crescente utilização de um instrumental tecnológico cada vez mais sofisticado, a Arqueologia também ampliou a sua interação com as Ciências Exatas e Ciências da Computação.

No século XXI temos o crescimento do número de pesquisadores e dos dados e problemas arqueológicos, analisados e interpretados de forma cada vez mais focada e especializada. Em outras palavras, o que vemos é a crescente especialização dos pesquisadores e da consciência da necessidade de projetos multidisciplinares. Isso, inclusive, gera uma diversificação na percepção, por parte dos pesquisadores, do que seja a episteme da Arqueologia.

Cada vez mais a vocação multidisciplinar confere para a Arqueologia uma identidade própria - como apontam alguns de seus profissionais (p. ex.: Lyman 2007). Isso, porém, não significa que a Arqueologia não tenha uma relação profunda com a Antropologia (Social e Cultural), pois as histórias intelectuais de ambas se aproximam e, em vários momentos se confundem. $\mathrm{O}$ que se pode assinalar é que a Arqueologia trata de algumas problemáticas e pode revelar aspectos não contemplados pela Antropologia. O importante, no entanto, é que apesar das particularidades do campo arqueológico, o diálogo entre a Arqueologia e a Antropologia é fundamental e profícuo para ambas, como vem sendo demonstrado desde o século XIX.

Um dos aspectos, a meu ver, extremamente interessante neste diálogo, na atualidade, diz respeito à problemática da preservação e significação do patrimônio arqueológico por parte de diferentes coletivos humanos. Há hoje um enorme interesse na preservação dos bens culturais do passado e isto tem várias razões: sociais, econômicas, políticas, identitárias, etc. Para alguns pensadores, a pós-modernidade e a suposta fluidez e instabilidade que ela trouxe, nos diferentes domínios de nossa existência faz com que, muitas vezes, os homens busquem no passado uma possível alternativa às inconstâncias do dia-a-dia (Hodder 
1999). Povos no mundo todo se valem da Arqueologia para ajudar a manter a particularidade de seus passados em face à globalização e a dominação ocidental, como uma estratégia para driblar a monotonia cultural.

Neste contexto, os arqueólogos são chamados para fora dos seus laboratórios, gabinetes, salas de aula e escavações. Eles são peças-chave nos debates sobre gerenciamento dos bens culturais, preservação do meio ambiente, identificação de territórios imemoriais. Enfim, são chamados a opinar na definição de diferentes políticas públicas. Assim, o arqueólogo se torna - como escreveu Hodder (1992) - um intérprete entre o passado e o presente e entre diferentes perspectivas sobre o passado.

Recentemente, vivenciei mais uma experiência interessante junto à população Asurini do Xingu, com quem convivo desde 1996 e que me levou a refletir sobre este novo contexto da pesquisa arqueológica e da importância de expandir suas fronteiras teóricas, metodológicas e temáticas. Não apenas em termos do diálogo com outras disciplinas científicas, mas também, com outros coletivos e modos de saber.

Os Asurini do Xingu, um grupo indígena Tupi, falante de uma língua pertencente à família linguística TupiGuarani, ocupa uma Terra Indígena localizada no estado do Pará, delimitada pelos municípios de Altamira e Senador José Porfírio. Sua aldeia está localizada à margem direita do rio Xingu, junto ao P.I. Kuatinemu, que é auxiliado pela unidade da FUNAI localizada em Altamira, Pará. Trata-se de uma popula- ção agricultora com uma dieta bastante diversificada que combina os recursos da roça (p.ex. milho, mandioca, batata, feijão, banana, etc) com os produtos da pesca, caça e coleta. Em termos sociais, eles têm no grupo doméstico a sua unidade social mais importante que tem, também, importância política e econômica. A sua vida ritual é dividida em dois complexos rituais fundamentais: O maraka - complexo ritual terapêutico e propiciatório - e o turé - complexo ritual em que se realizam os ritos associados à guerra, morte $\mathrm{e}$ iniciação dos jovens. Com relação à produção da cultura material, na qual homens e mulheres dedicam grande parte do seu tempo, os Asurini são reconhecidos pela maestria artesanal e por um apurado senso estético.

Esta população indígena foi contatada em 1971 pelo Pe. Anton Luckesh e, em 1972, pela FUNAI. No período do contato, os Asurini estavam distribuídos em pequenos acampamentos, próximos às margens do Igarapé Ipiaçava e na aldeia Taiuviaka. Após o contato, esta aldeia e acampamentos foram sendo aos poucos abandonados e eles instalaram novas aldeias (Akapepungui e Kuatinemu). Em 1982 eles foram transferidos para a aldeia atual, na margem direita do rio Xingu, também chamada de Kuatinemu. Segundo os Asurini, o contato com os brancos (FUNAI) foi uma necessidade de sobrevivência diante do que eles acreditavam ser o fim eminente de seu povo. Este motivado pelos ataques que eles sofriam há anos de outros indígenas (p.ex. Kayapó e Araweté) e pelas doenças transmitidas 
pelos brancos (p.ex. gateiros, castanheiros, etc) invasores de seu território. A história dos Asurini é repleta de belicosidade, baixas populacionais e de deslocamentos e perdas territoriais. Mesmo depois do contato, eles continuaram a sofrer com as doenças transmitidas pelos brancos. Isto gerou um desequilíbrio na sua pirâmide etária, com graves consequências culturais.

Em maio de 2010 realizei mais uma pesquisa arqueológica e etnoarqueológica na T.I. Kuatinemu, como parte das atividades do projeto intitulado Território e História dos Asurini do Xingu: um estudo bibliográfico, documental, arqueológico e etnoarqueológico sobre a trajetória histórica dos Asurini do Xingu (século XIX até os dias atuais), coordenado por mim e financiado pela Fundação de Amparo à Pesquisa do Estado de São Paulo (FAPESP). Este projeto foi elaborado com o objetivo de contar uma parte desta história e contribuir para a preservação da memória Asurini e sobre sua trajetória, como legado às novas gerações.

O projeto de pesquisa foi desenvolvido contemplando vários aspectos e estratégias metodológicas da arqueologia colaborativa: 1) os Asurini participaram na elaboração da proposta e na definição da logística do projeto; 2) foram os guias na expedição pelo igarapé Ipiaçava, definindo os locais de acampamento e indicando a localização dos sítios a serem pesquisados; 3) foram contratados como auxiliares no levantamento do potencial arqueológico da área e na logística da expedição pelo Ipiaçava; 4) foram responsáveis pela elaboração de parte do material audiovisual.
Foram doze dias intensos de viagem pelo Ipiaçava durante os quais localizamos três antigos assentamentos Asurini, todos sobre antigos sítios arqueológicos. Um total de 55 pessoas (homens, mulheres e crianças) seguiram nesta jornada (re)visitando locais abandonados pelos Asurini há pelo menos quarenta anos. Um verdadeiro retorno ao passado e uma experiência sobre a memória e significado dos lugares.

"Eu e Tukura ficamos sentados na capoeira próxima da aldeia Taiuviaka e ficamos conversando sobre como teria sido a vida dos velhos ali naquele lugar, o que eles teriam passado, como deve ter sido difícil para eles ficar fugindo dos outros índios ... quase dava para a gente sentir o que eles tinham passado ali" (Depoimento de Ajé Asurini, um dos jovens líderes Asurini e presidente da Associação Indígena Awaeté).

No que se refere à pesquisa arqueológica o aprendizado em campo foi imenso, pois a articulação do ponto de vista ocidental com o ponto de vista indígena sobre a arqueologia da área me fez refletir sobre a minha prática como cientista e, especialmente, sobre o meu trabalho de quatorze anos com os Asurini do Xingu.

Durante todo o trabalho debati com os meus colaboradores índios sobre temas como a origem e expansão dos povos Tupi, o surgimento dos Asurini do Xingu como população indígena, a natureza e a autoria dos vestígios arqueológicos. Todas as reflexões Asurini foram pautadas em sua filosofia ameríndia sobre a relação entre os humanos, a natureza e a sobrenature- 
za. Os mitos de Ajaré, Tauvuma, Maíra foram o substrato para as explicações Asurini sobre a sua trajetória e de seus antepassados (Silva 2002).

Numa noite antes da viagem ao Igarapé Ipiaçava e depois de uma longa conversa com alguns jovens sobre estes temas e de explanar com relativo detalhe as explicações linguísticas, antropológicas e arqueológicas que situam a origem dos povos Tupi no sudoeste da Amazônia tive minha explicação questionada por um Asurini:

"Sabe Fabíola, esta explicação pode estar certa para os outros índios, mas não para os Asurini. Eu confio na nossa explicação. Eu acredito que nós nascemos de Uirá e Ajaré... e as panelas que a gente encontra são de Anumai. Eu acredito nesta história porque ela vem de muito tempo... contada de pai para filho... não se perde... não se esquece... por isso que ela é a mais certa prá mim" (Kwain Asurini, jovem liderança indígena, vice-presidente da Associação Indígena Awaeté).

Quando retornamos à aldeia, na noite anterior a minha volta para Altamira, Kwain me disse que talvez eu estivesse parcialmente certa e que nem todo o material cerâmico encontrado fosse de Anumai... talvez os que estivessem abaixo fossem de outros índios.

Diante desta experiência e da interlocução com os Asurini eu me fiz uma pergunta: Qual é o papel do arqueólogo? Produzir e disseminar o conhecimento arqueológico sobre o passado? Facilitar o envolvimento do passado em um presente multicultural?
Particularmente, como profissional da arqueologia, acredito que nossa prática e interpretação sobre o passado devam levar em consideração as múltiplas vozes interpretativas sobre a trajetória humana no passado. Nós não somos os donos do passado, mas talvez, sejamos um profissional cuja responsabilidade está em possibilitar esta tradução multivocal do passado no presente. É preciso descolonizar a construção do conhecimento arqueológico.

Este movimento de "descolonização" da arqueologia, no entanto, não é uma tarefa fácil, tanto pelas populações indígenas como a comunidade científica e demais agentes envolvidos com demandas em territórios indígenas. Inúmeras reflexões têm sido feitas sobre os problemas e as possibilidades de se trabalhar com esta perspectiva alternativa, dialógica e reflexiva de produção do conhecimento arqueológico sobre estes povos.

Alguns dos aspectos mais relevantes e, também, mais difíceis de serem levados a cabo neste movimento pela descolonização da prática arqueológica em territórios indígenas dizem respeito à interpretação e construção do conhecimento sobre o patrimônio arqueológico e à sua divulgação e disseminação a partir de uma perspectiva intercultural. Normalmente, os arqueólogos não estabelecem parcerias com os povos indígenas para a interpretação ou divulgação dos dados pesquisados. Isto acontece, principalmente, porque os modos de conhecer dos arqueólogos e indígenas não são os mesmos e isto dificulta uma compreensão consensual sobre os fenômenos observados. Neste 
sentido, a construção intercultural do conhecimento e a parceria no processo de divulgação deste conhecimento só podem ser realizadas a partir de uma perspectiva multivocal (p. ex. Isaacson $\&$ Ford 2005). Por fim, resta concordar com Jackson e Smith (2005:346):

"A descolonização da arqueologia indígena na prática envolve uma redefinição dos papéis, direitos e responsabilidades tanto dos arqueólogos como dos povos indígenas... tem de envolver uma mudança nas relações de poder".

\section{REFERÊNCIAS}

Ferreira, L. M. 2010. Território Primitivo: a Institucionalização da Arqueologia no Brasil (19870-1917). Porto Alegre: EDIPUCRS.

Hodder, I. 1992. Theory and Practice in Archaeology. London/New York: Routledge.

Hodder, I. 1999. The Archaeological Process. Oxford: Blackwell Publishers Ltd.

Isaacson, K. e S. Ford. 2005. Looking forward - looking back: shaping a shared future, in Indigenous Archaeologies. Decolonizing theory and practice. Editado por C. Smith e H. Martin Wobst. London: Routledge. pp. 354-367.

Jackson, G. e C. Smith. 2005. Living and learning on Aboriginal lands; decolonizing archaeology in practice, in Indigenous Archaeologies. Decolonizing theory and practice. Editado por C. Smith e H. Martin Wobst. London: Routledge. pp. 328-351.

Lyman, R. L. 2007. Archaeology quest for a seat at high table of Anthropology. Journal of Anthropological Archaeology. 26:133-149.

Rodrigues, J. E. R. 2006. Da proteção jurídica ao patrimônio cultural, in Patrimônio: atualizando o debate. Editado por V. H. Mori;
M. C. de Souza; R. L. Bastos e H. Gallo. São Paulo. pp. 233-240. Instituto do Patrimônio Histórico e Artístico Nacional - IPHAN.

Silva, F. A. 2002. Mito e Arqueologia. A interpretação dos Asurini do Xingu sobre os vestígios arqueológicos encontrados no parque indígena Kuatinemu - Pará. Horizontes Antropológicos. Arqueologia e sociedades tradicionais. 8(18): 175-187.

Recebido em 20/07/2011.

Aprovado em 02/09/2011. 